\title{
Impact of a Lower Conservation Budget on Road Safety Indices
}

\author{
M. Rojo $\mathbb{D},{ }^{1}$ H. Gonzalo-Orden $\mathbb{D},{ }^{1}$ A. Linares $\mathbb{D}^{1},{ }^{1}$ and L. dell'Olio $\mathbb{D}^{2}$ \\ ${ }^{1}$ Department of Civil Engineering, University of Burgos, Burgos 09001, Spain \\ ${ }^{2}$ Department of Transports, University of Cantabria, Santander 39005, Spain \\ Correspondence should be addressed to M. Rojo; mrarce@ubu.es
}

Received 26 April 2018; Revised 11 July 2018; Accepted 22 July 2018; Published 30 July 2018

Academic Editor: Sara Moridpour

Copyright (C) 2018 M. Rojo et al. This is an open access article distributed under the Creative Commons Attribution License, which permits unrestricted use, distribution, and reproduction in any medium, provided the original work is properly cited.

\begin{abstract}
Over the past few years, several countries, including Spain, have been experiencing a period of economic recession. As a result, these governments have reduced their budgets for transport infrastructures (both construction and maintenance operations). The main objective of this study is to analyze whether these budget reductions have an effect on increased accident rates and to perform an assessment of their real economic benefit. Thus, we analyze whether significant changes over recent years are perceptible in the road safety indexes in Spain, in terms of risk, accident fatality, and accident severity. The relation between lower budgets and higher road safety indices is analyzed through linear regression techniques. The results show a strong relation between the Risk Index and the maintenance budget, measured as an average of the last years. In addition, a final economic assessment demonstrates that this reduction in investment had no real economic benefits, especially as the costs of the accidents exceeded the savings in the conservation plans.
\end{abstract}

\section{Introduction}

The consequences of the current economic crisis have affected many countries over the past few years, which have meant that government road construction and maintenance budgets have been reduced. Another consequence of the economic recession is the high reduction in the number and length of journeys by road.

Thus, if we take into account the fact that the number of accidents has remained constant over the past few years, even though traffic volumes are lower, we can conclude that the risk of an accident per kilometre of road has in fact increased. In this paper, a possible relationship between lower construction and conservation budgets and the ratio of accidents is assessed.

To do so, we need to locate the key parameter to analyze this relationship. If we look at the bibliography, we can see different points of view. Hakim et al. [1] presented a critical review of state-of-the-art macro models for road accidents, to identify which variables are more effective, in order to improve levels of road safety: vehicles-kilometre, vehicle fleet, income (in its various forms), percentage of young drivers, intervention policies such as speed limits, periodic vehicle inspection, and minimum alcohol-drinking age. Zou and Yue
[2] studied the causes of road accidents by using a Bayesian Network approach. Rifaat and Chin [3] analyzed the severity of accidents using ordered probit models, giving broad consideration to driver characteristics, roadway features, vehicle types, pedestrian characteristics, and crash characteristics.

Chin and Tan [4] adapted the techniques usually employed for road safety audits in Singapore, in order to develop a Road Safety Performance Rating for the quantitative evaluation of safety deficiencies. The application of road safety audits began there in 1998, though they are named "safety reviews", as they are not a compulsory checklist to approve a project. Even more, since the review process is usually qualitative in nature, there are some doubts about their significance and their utility. Hence, the authors developed a quantitative approach to obtain a Road Safety Performance Index (RSPI), a related Road Safety Performance Chart (RSPC), and a Road Safety Performance Rating (RSPR) that can serve as a benchmark for comparisons between various road projects.

In addition, de Leur and Sayed [5] analyzed the objectives that a Road Safety Risk Index must achieve and how to develop it correctly. Hermans et al. [6] focused on an essential step in the construction process of a composite road safety performance indicator: the assignment of weights to the 
TABLE 1: Evolution of investment in roads [21].

\begin{tabular}{lccc}
\hline Year & $\begin{array}{c}\text { Overall road budget } \\
(\mathrm{M} €)\end{array}$ & $\begin{array}{c}\text { Road construction } \\
\text { budget (M€) }\end{array}$ & $\begin{array}{c}\text { Road maintenance } \\
\text { and safety budget } \\
(\mathrm{M} €)\end{array}$ \\
\hline 2008 & 4,778 & 2,822 & 1,219 \\
2009 & 5,414 & 2,886 & 1,324 \\
2010 & 5,114 & 3,478 & 1,257 \\
2011 & 3,011 & 1,445 & 1,085 \\
2012 & 3,160 & 1,268 & 873 \\
2013 & 2,963 & 1,084 & 818 \\
2014 & 2,153 & 1,148 & 818 \\
2015 & 2,194 & 1,154 & 935 \\
2016 & 2,383 & 1,174 & 1,058 \\
2017 & 2,121 & 955 & 958 \\
\hline
\end{tabular}

individual indicators. Holló et al. [7] highlighted the limitations of road safety performance indicators, based on examples of certain countries from Central Europe, to conclude that exposure and the socioeconomic climate appear to have a high impact on road safety. Finally, Mannering et al. [8] and Kumar et al. [9] noted the heterogeneity of road-accident data and their specific analyzes which took that issue into account. A similar analysis was conducted by Imprialou and Quddus [10], who studied how to improve the data collection of accidents, in order to achieve a more usable database.

Various studies have analyzed the effects of socioeconomic variables on road safety [11-15]. However, it now appears to be of interest to study them once more, since the characteristics of both roads and economy have changed considerably. Law et al. [16] analyzed the effects of the recent economic crisis and the Motorcycle Safety Programme (MSP) on motorcycle-related accidents, casualties, and fatalities in Malaysia. Although their analysis found a reduction in the number of motorcycle-related accidents and fatalities, the authors concluded that the MSP was the main cause for this reduction, with no signs of separate effects due to the economic crisis. On the contrary, Yannis et al. [17] analyzed the effect of annual changes in Gross Domestic Product (GDP) on annual changes in mortality rates, by employing some mixed linear models for 27 European countries over the period between 1975 and 2011. They concluded that a GDP increase is associated with an increase in mortality rates. Yanqun et al. [18] and Goniewicz et al. [19] analyzed traffic safety at a global level and proposed some possible actions and programs for its improvement. Finally, Loo et al. [20] developed an exhaustive review of road safety strategies in Hong Kong, concluding that significant improvements would require the restructuring of road safety activities.

Following this introduction to the problem, Section 2 will show the evolution of the road safety parameters over the years that are under study. Comparisons between risk levels and budgets will be presented Section 3, and the relations between them will be analyzed with linear regression techniques and discussed. Likewise, an economic assessment of the effects of lower budgets will be set out. Finally, the last section will offer some concluding remarks and a summary of the main findings of the study.

\section{Data Analysis}

In this section, the data during the recession period (20092014) will be analyzed, both economically and from the point of view of road safety. Thus, it is important to establish the extent of the budget reductions for road construction and maintenance, in order to relate it to possible increases in the risk indexes.

The data reflect economic issues, especially the budget allocations for road works, dividing them into the construction of new roadways and conservation and maintenance operations for the network. In addition, the vehicle fleet and the total volume of registered traffic flows (measured in vehicles per $\mathrm{km}$ ) are also studied. Finally, with regard to the data on safety, both the accident injury rates and the amount of fatalities (within a period of 30 days from the accident) are analyzed. The period of analysis is between 2008 and 2016, allowing us to visualize the evolution of all these parameters during the economic crisis. These data were mainly gathered from various websites of the Spanish Government, as specified in the following sections.

2.1. Economic Analysis. Firstly, it is necessary to establish the annual budget for road construction and maintenance works. The country under analysis is Spain, so the data were gathered from statistical sources available from the Ministry of Public Works Spanish Government [21].

The last deep recession in Spain lasted from 2009 to 2014, although data were obtained from 2008 to 2017, in order to gain a complete overview of the evolution of the budgets. In addition, we have classified them by construction and maintenance budgets, because of their different characteristics and their impact on road safety. The figures for this period are shown in Table 1.

Firstly, we can note that both the road construction and the maintenance budgets decreased significantly between $2009 / 2010$ and 2013. Specifically, the reduction amounted to $69 \%$ for the road construction budget between 2009 and 2013 
TABLE 2: Evolution of accidents [23-26].

\begin{tabular}{lcccc}
\hline \multirow{2}{*}{ Year } & \multicolumn{3}{c}{ Injury Accidents } & \multicolumn{2}{c}{ Fatalities (30 days) } \\
& Value & $\Delta$ previous year & Value & -- \\
\hline 2008 & 43,831 & -- & 2,466 & $-14 \%$ \\
2009 & 40,789 & $-7 \%$ & 1,928 & $-9 \%$ \\
2010 & 39,174 & $-4 \%$ & 1,603 & $-17 \%$ \\
2011 & 35,878 & $-8 \%$ & 1,442 & $-10 \%$ \\
2012 & 35,425 & $-1 \%$ & 1,230 & $-15 \%$ \\
2013 & 37,297 & $5 \%$ & 1,247 & $1 \%$ \\
2014 & 35,147 & $-6 \%$ & 1,248 & $0 \%$ \\
2015 & 34,558 & $-2 \%$ & 1,291 & $3 \%$ \\
2016 & 36,721 & $6 \%$ & & \\
\hline
\end{tabular}

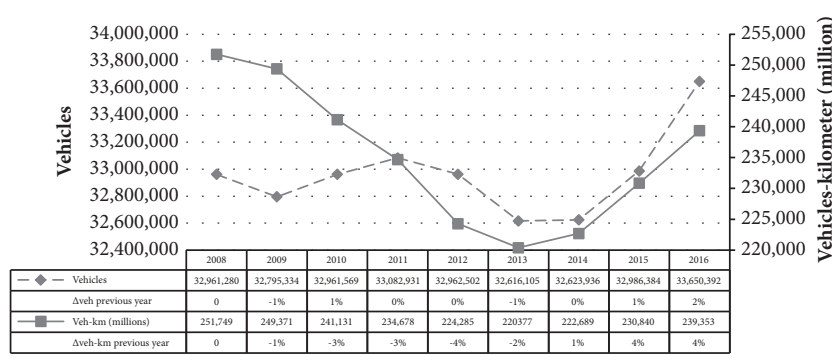

FIGURE 1: Evolution of vehicle fleet and registered traffic [22, 23].

and a 38\% for maintenance and safety operation from 2010 to 2013. Once this period was over, the budgets began to rise again in 2015, achieving similar values of 2011/2012 by the end of 2016, very much lower compared with the previous ones. Moreover, in 2017, they were decreased again in a very high proportion. It is important to note that the division of these budgets has been slightly different since 2015 , so the data are not completely comparable.

On the other hand, it is interesting to compare these values with the traffic volumes supported by the road in these years. Figure 1 shows how both the vehicle fleet volume and the recorded traffic flows on interurban tracks evolved during the period under consideration.

We can note that although the size of the vehicle fleet increased in 2011, there were two "troughs" for the vehicle fleet: in 2009 and 2013. Following that year, it underwent slight increases in 2014, compared with the previous year. On the other hand, if we analyze the traffic volumes (measured in vehicle-kilometres travelled), we can see a continuous descendent trend from 2008 to 2013, after which its minimum value increased, coinciding with the severest years of the economic crisis, although that trend changed in 2014, with a slight growth that continued until 2016.

Finally, if we analyze the distribution of the vehicle fleet, we can see that, in 2016 (the most recent year with published statistics), $71 \%$ of vehicles were cars, $15 \%$ were trucks and vans, $10 \%$ were motorcycles and mopeds, and the remaining $4 \%$ were buses, tractors, and other vehicles types. More interesting is the fact that, in 2016, the average age was 11.5 years for light vehicles and 13.5 years for trucks and vans [23], demonstrating how the vehicle fleet in Spain was affected by suffered the economic crisis, as were other sectors.

2.2. Road Safety Analysis. In this section, we analyze the accident statistics corresponding to the same period. Table 2 shows the number of accidents and the number of fatalities (within 30 days) on Spanish roads. There, we can see that, in general terms, both data are descending during the period of the economic crisis, while the number of accidents experienced only slight growth between 2012 and 2013, reaching its historical minimum value in 2015 . On the contrary, the number of fatal victims was higher than the minimum in 2013 , and since that year it increased slightly.

It is obvious that increasingly effective passive safety systems in modern vehicles would probably have influenced the fatality and severity indices, since personal injuries are fortunately reduced by a high percentage. However, the fact that there was no increase in accidents after a certain date (even when the traffic volumes increased) appears to point to a relationship with the budget reductions for roads and, therefore, for road maintenance.

To verify this hypothesis, the standard road safety indices were calculated: risk, fatality, and severity indexes. The probability of traffic accidents occurring for each driven kilometre is shown by the Risk Index. In the case of the Fatality Index, the likelihood of death in a traffic accident is a quantifiable value. Finally, the Severity Index indicates the probability of dying once an accident has been occurred. Equations (1) to (3) show the expressions to obtain these indices [27]:

$$
\begin{aligned}
& \text { Risk Index }=R I \\
& \quad=\frac{\text { Number of accidentes involving victims }}{10^{8} \text { vehicles }- \text { kilometre }} \\
& \text { Fatality Index }=F I \\
& \quad=\frac{\text { Number of fatalities (within } 30 \text { days) }}{10^{8} \text { vehicles }- \text { kilometre }} \\
& \text { Severity Index }=\text { SI } \\
& \quad=\frac{\text { Number of fatalities (within } 30 \text { days) }}{100 \text { accidentes involving victims }}
\end{aligned}
$$




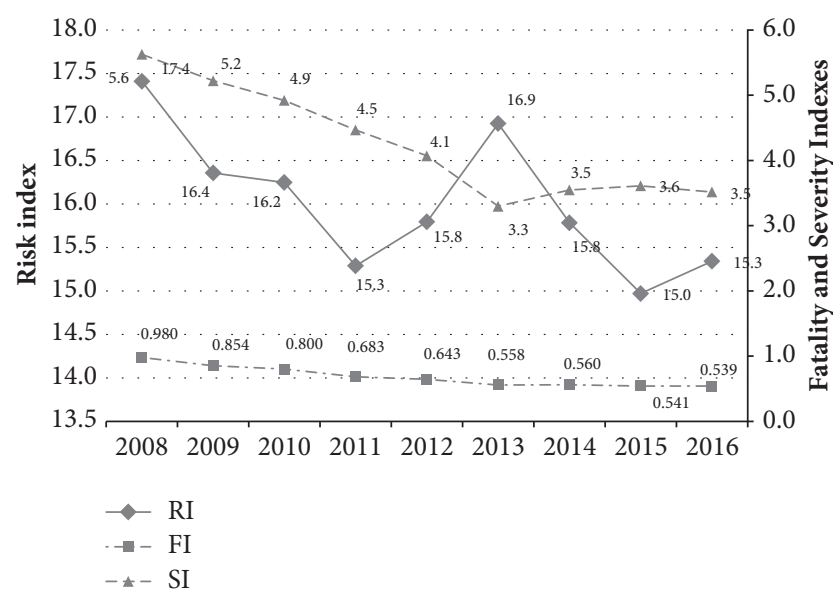

Figure 2: Evolution of the Road Safety Indices.

These indexes can be employed to analyze and, in some cases, even to forecast the accidents rate and their consequences, as proposed by Commandeur et al. [28].

Employing the data presented in Figure 1 and Table 2, we can calculate each one of these indices. The results are shown in Figure 2, where we can see that both the Fatality and the Severity Indexes show a decreasing trend, except in 2014, with a slight increase in the FI compared with previous years. Nevertheless, the trend of the Risk Index is clearly opposed, with an initial minimum in 2011, but followed by a high increase until 2013, coinciding with the last few years of the economic recession, and then another low value in 2015.

As previously noted, the passive safety systems of automobiles, increasingly more sophisticated and efficient, are one of the main causes of the decrease in both the Fatality and the Severity Indexes. But the Risk Index is related more to the state of the road (and to the active safety systems of vehicles, as well), so we can analyze whether the reduction in conservation and maintenance budgets might have had some influence on its dramatic growth between 2011 and 2013.

This hypothesis agrees with Hakkert et al. [29], who discussed the problems associated with the use of exposure and risk and gave examples of various safety studies. Their conclusion was that these terms should in practice be defined within the context of the issue under study. For each application, the correct exposure measure should be used: in the case of transport, the most widely used measure of exposure was the number of kilometres travelled for each travel mode (vehicles-kilometre travelled). In addition, Chan, Huang, and Yan [30] studied the effect of asphalt pavement conditions on traffic accidents, by using negative binomial regression models.

\section{Comparison between Economic and Accidents Data}

In this section, the economic and the road safety data presented in the previous chapters will be compared, in order to analyze the influence of one on the other. Initially, the possible existence of a relationship between the annual road budgets (overall or only for conservation purposes) and safety indexes will be discussed. Afterwards, a brief economic assessment of this relationship will be done, by comparing the savings in maintenance with the eventual higher costs due to accidents.

\subsection{Relationship between Annual Budgets and Safety Indexes.}

The possible relationship between the data gathered on annual budgets and the rate of endangerment will be analyzed. The reasons for selecting this ratio are due to the lower influence of passive safety systems, increasingly sophisticated and widespread in the vehicle fleet, on the Risk Index, rather than the calculated ones.

Thus, we employed regression techniques to determine the possible correlation between the different budgets and the Risk Index. Even though the results of various types of regression tests were quite similar, we finally chose the linear models. As previously mentioned, the budget data between 2009 and 2014 were included in the analysis, as the rest of the data were not directly comparable, due to the change in their structures.

In Figure 3, the relations between the road budgets and the Risk Index of the following year are shown, as the impact of a low conservation budget was not immediately detected, except for a certain period. Figure 4 shows the same effect two years later. We can observe that the trends in these figures show an increase in both the slope of the regression line and the R2 index over time. However, the R2 indexes were not strong enough in some cases.

Finally, rather than with the budgets of the preceding year, the analysis of the relation of the Risk Index, with the average of the previous years, is even more illustrative. Figures 5 and 6 show the results of this relationship. There we can see that not only that the gradient of the regression line grows (in an absolute value), but also that the coefficients of determination R2 started to reach significant values: higher than 95\% with the budgets over the 3 preceding years.

Therefore, we can conclude this section by pointing out that that there is a relationship between the budgets for roads and their endangerment. This relationship is much more clear and intense when we specifically analyze budgets for maintenance operations. We can also see that a decrease in the maintenance budget has an effect on the Risk Index for the following years, because the deterioration of roadways has a higher impact on road safety over subsequent years rather than in the year that corresponds to the budget allocations. If instead of considering the annual value of budgets, we take the average of the previous years (much more realistic), the coefficient of determination reaches levels that are higher than $95 \%$, which are considerably significant for our purposes.

3.2. Economic Assessment. Finally, in this section, we will analyze whether these reductions in road budgets are economically profitable or whether the costs associated with the new accidents outweigh the savings. For this purpose, we shall employ the regression line obtained in Figure 6, which shows the relationship between the Risk Index (RI) and the 

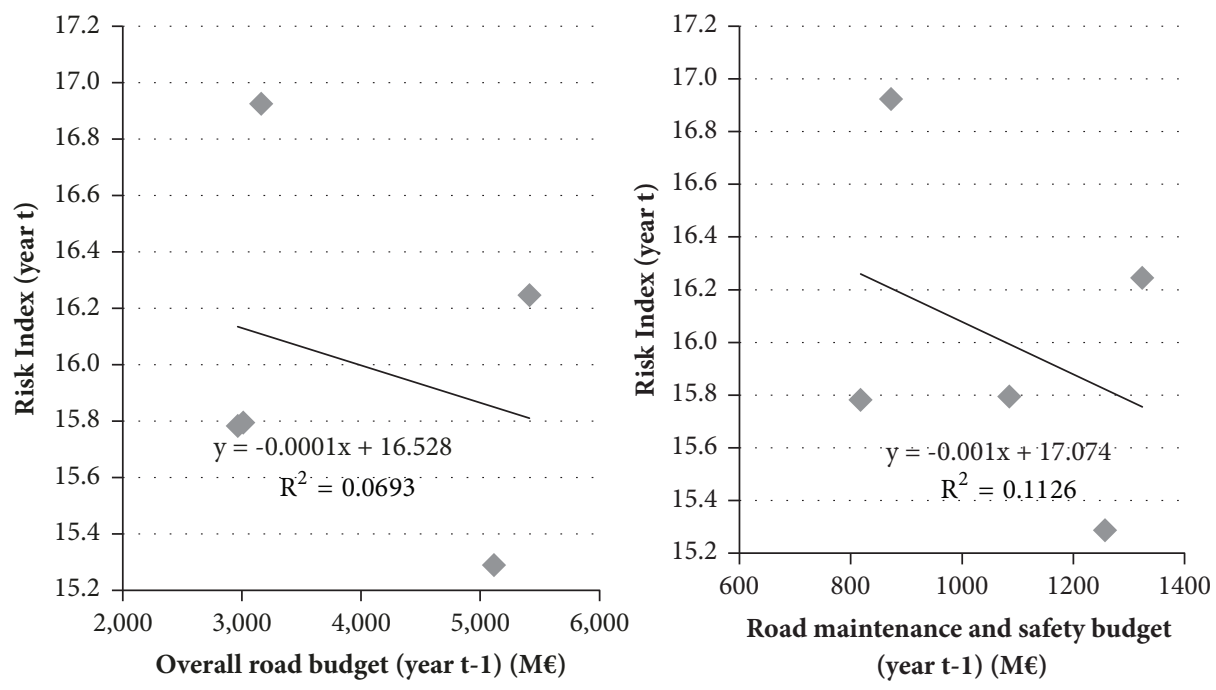

Figure 3: Relationship between Risk Index (year t) and Road Budgets (year t-1).
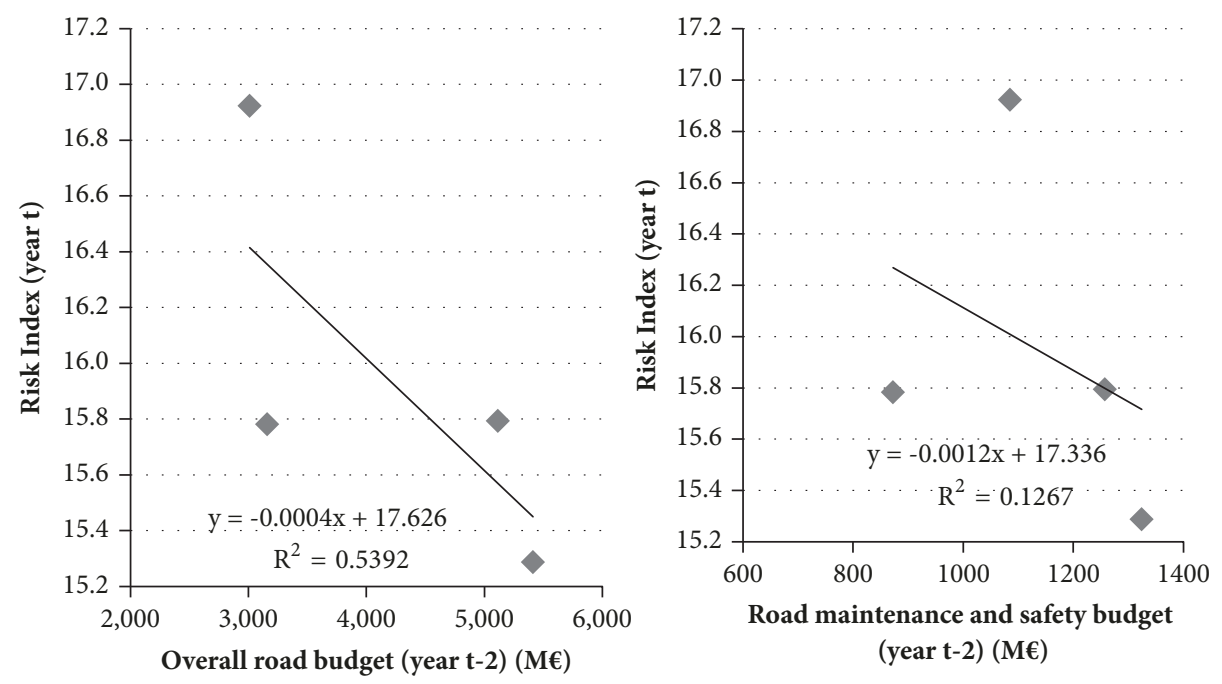

Figure 4: Relationship between Risk Index (year t) and Road Budgets (year t-2).

average road maintenance budget over the previous 3 years, in millions of Euros $\left(\mathrm{MB}_{3}\right)$. This equation is presented in the following:

$$
R I=25.695-0.0082 \cdot M B_{3}
$$

Combining this equation with (1), we can directly relate the maintenance budget to the number of accidents involving victims (AV) and the traffic volume measured in vehicleskilometre travelled (VKT), as shown in the following:

$$
\begin{aligned}
R I & =\frac{A V}{V K T\left(10^{8}\right)}=10^{8} \cdot \frac{A V}{V K T} \longrightarrow \\
A V & =\frac{V K T}{10^{8}} \cdot\left(25.695-0.0082 \cdot M B_{3}\right)
\end{aligned}
$$

Thus, once we have established the real number of VKT over the last few years of the recession, we can estimate how many accidents could have been produced, if the budgets had been maintained at the same levels before the economic crisis. As we can see in Table 1 , the $\mathrm{MB}_{3}$ has varied during the period of study, in a range from $1267 \mathrm{M} €$ in 2011 (average from 2008 to 2010) to $925 \mathrm{M} €$ in 2014 (average from 2011 to 2013).

Therefore, we propose, in view of the real value of VKT in each year, three different scenarios: Scenario 1 with the highest budget values at all times; Scenario 2 with the average of these margins; and Scenario 3 with the real values. These scenarios and their corresponding estimated number of accidents are shown in Table 3.

Comparing these values with those presented in Table 2, we can see that more than 3,900 accidents involving victims could have been avoided, had the road maintenance budgets remained constant at the same levels as 2011 (scenario 1). Even in the intermediate hypothesis (scenario 2), roughly 1,300 accidents could have been prevented between 2012 and 2013 . 

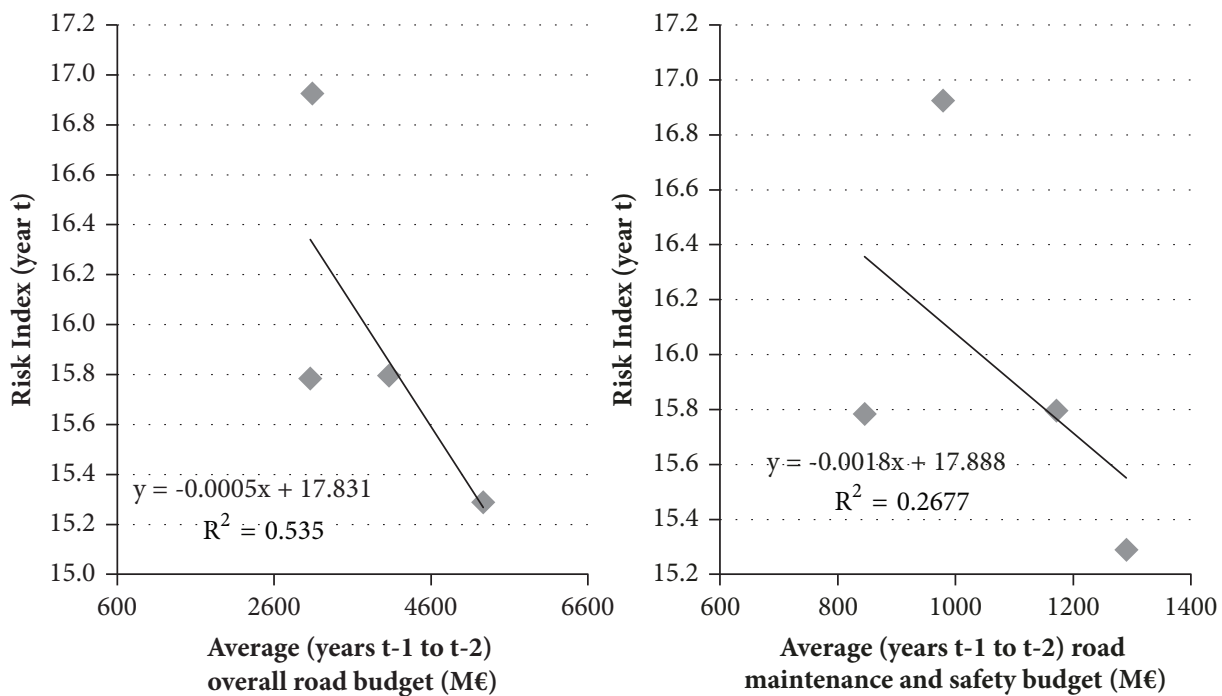

Figure 5: Relationship between Risk Index and Average Values of Road Budgets (2 previous years).
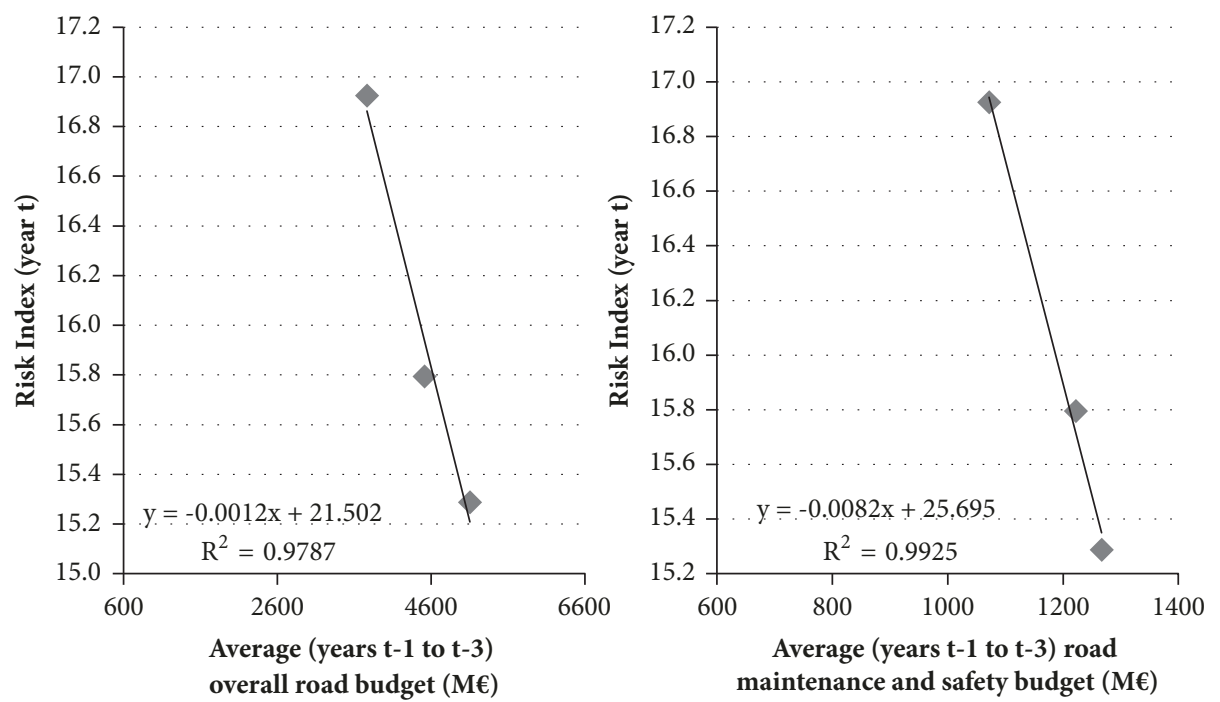

FIGURE 6: Relationship between Risk Index and Average Values of Road Budgets (3 preceding years).

TABLE 3: Estimated value of AV with higher conservation budgets.

\begin{tabular}{|c|c|c|c|c|c|c|c|}
\hline \multirow{2}{*}{ Year } & \multirow{2}{*}{ VKT (millions) } & \multicolumn{3}{|c|}{$\mathrm{MB}_{3}(\mathrm{M} €)$} & \multicolumn{3}{|c|}{ AV estimated } \\
\hline & & Scenario 1 & Scenario 2 & Scenario 3 & Scenario 1 & Scenario 2 & Scenario 3 \\
\hline 2011 & 234,678 & 1,267 & 1,267 & 1,267 & 36,559 & 36,559 & 36,559 \\
\hline 2012 & 224,285 & 1,267 & 1,244 & 1,222 & 34,940 & 35,351 & 35,761 \\
\hline 2013 & 220,377 & 1,267 & 1,169 & 1,072 & 34,331 & 36,093 & 37,855 \\
\hline 2014 & 222,689 & 1,267 & 1,096 & 925 & 34,691 & 37,808 & 40,924 \\
\hline
\end{tabular}

TABLE 4: Estimated incremental cost because of the increased Risk Index.

\begin{tabular}{ccccccc}
\hline \multirow{2}{*}{ Year } & \multicolumn{2}{c}{$\begin{array}{c}\text { Estimated Increase of Fatalities } \\
\text { Scenario 1 }\end{array}$} & Scenario 2 & \multicolumn{2}{c}{ Estimated Increase of Injured } & \multicolumn{2}{c}{ Estimated Increase of Cost (M€) } \\
& 20 & 3 & Scenario 1 & Scenario 2 & Scenario 1 & Scenario 2 \\
\hline 2012 & 98 & 40 & 7,203 & 184 & 208 & 32 \\
2013 & 16 & -- & 1,261 & 2,948 & -240 & 503 \\
2014 & 16 & -- & 207 & -- \\
\hline
\end{tabular}


The next step was to establish an economic value for each accident with victims. Three different methodologies for its estimation were identified in the bibliography [31]:

(i) Compensation method: based on the average compensation paid by insurance companies to accident victims or their families

(ii) Human capital method: based on calculations of production losses, adding occasionally a certain percentage to represent the pain and human suffering associated with traffic accidents

(iii) The willingness to pay method: based on stated preference surveys, where interviewees have to say what amount of money they are willing to pay for a certain reduction in the risk of an accident.

One of the most recent studies in Spain on this topic is the document prepared by FITSA [31], which determines that the unit cost ranged, according to the method used, between 349,687 and 857,648 Euros per fatality. Since these values were very low, compared with those corresponding to other European countries, we took the higher ones, because there were no subsequent studies in Spain. Finally, the New Zealand Ministry of Transport [32] estimated the costs of serious injuries at $18.56 \%$ of those corresponding to fatalities. Thus, we were able to assume an average value of $€ 159,173$ per injured person.

We can therefore estimate how many fatalities could be avoided, basing our study on the values presented in Table 3 and Figure 2 (Severity Index) and the data relating to the average number of injured in each accident [25]. If we transform it into monetary units, we can determine the incremental cost for Spain, because of the increase of the Risk Index in its roads. These calculations are presented in Table 4.

If the conservation budgets had remained constant at the same levels as 2011 (scenario 1), over $1650 \mathrm{M} €$ could had been saved in terms of accident-related costs during the period under consideration. Even in the intermediate hypothesis (scenario 2), this incremental estimated cost of accidents is higher than $500 \mathrm{M€}$. By analyzing Table 1, we can see that the savings in the conservation budget from 2011 to 2014 amounted to a total amount of $746 \mathrm{M} €$. Therefore, we can conclude that for each Euro not spent on the maintenance of roads generated a cost of traffic accidents within a range of between 0.7 and 2.2 Euros. There are also studies that have affirmed that if the trends towards further reductions remained unmodified, then after some years the reconstruction of the network would be needed, so the final cost would considerably increase [33].

Thus, even if we were not to consider the economic assessment, the savings in conservation and maintenance budgets were not acceptable in terms of road safety. Human life is so important that no economic assessment can be considered when we are considering accidents that bring nothing but human pain and suffering.

\section{Conclusions}

In this paper, the effects of the economic recession in certain countries and especially Spain on road safety have been analyzed. This crisis has modified both the amounts invested in road infrastructure, construction of new roadways or maintenance of the existing ones, and the traffic flowing through them, making them decrease. However, much more important is the impact of these issues on the safety indexes, which directly affects the relative number of accidents.

According to our results, we can underline six main conclusions:

(i) The overall road budget has considerably decreased during the years of recession. Over the period between 2008 and 2017 the road construction budget diminished by $66 \%$, while the maintenance and conservation budget decreased by $21 \%$ in the same period. However, if we take the maximum and minimum values, we can see a decrease of $73 \%$ in the construction budget between 2010 and 2017 and of $38 \%$ in conservation and maintenance between 2009 and 2013.

(ii) Concerning the traffic circulating on Spanish roads, we have noted similar decreasing trends between 2008 and 2013, the year with the minimum number of registered vehicles-kilometres. The traffic in 2013 was $12 \%$ lower than the traffic in 2008 . However, in 2014, this trend started changing, noting a growing comparing with the previous years.

(iii) From a different point of view, the number of fatalities has fortunately continued its downward trend, except since 2013, when a slight increase once again appeared. However, the number of accidents involving injuries significantly decreased between 2008 and 2012 by $19 \%$, but has remained constant or even higher since that year.

(iv) The fatality index, which is related to the above data, has fortunately been decreasing each year during the period under analysis. However, the Risk Index achieved a minimum value in 2011, but underwent a high, $11 \%$, increase over the following two years. We considered that this index was the most representative, since the others were influenced by the passive safety of vehicles to a greater extent. These systems are, fortunately, more and more advanced and therefore prevented deadly casualties in the case of accidents involving severe injuries.

(v) If we study the relationship between this Risk Index with the road conservation and maintenance budgets, we see a real correlation between the average maintenance budget over the preceding years and the possibilities of having an accident in the actual one. This correlation is defined by the determination coefficients, which reached a value of $27 \%$ when analyzing the preceding two years and $99 \%$ over the preceding three years.

(vi) Finally, if we try to assess the economic impact of these two opposing variables, lower budgets and higher Risk Indices, we can determine that this reduction of conservation budgets does not lead to a real saving, 
as the cost of the additional accidents was higher (by between 0.7 and 2.2 times). Additionally, the maintenance (or reconstruction) costs in the future will grow much more than the usual amount, such that the effect of negative savings were even higher, added to the human tragedy associated with road traffic accidents, fatalities, and victims.

Hence, we can conclude by underlining the relationship between the road infrastructure investment budgets and the associated safety indexes. This relation cannot be ignored, because any decrease in maintenance budgets will eventually provoke a fatal accident. Even if we consider the problem in economic terms, each Euro invested in the conservation of roads is more than compensated in terms of fewer accidents.

We should encourage the relevant authorities to continue investing in road infrastructure even in economic recession periods, particularly in maintenance and conservation operations (other large investments in transport could instead be reduced), as investment in maintenance affects the accident rate on our roadways, with several economic consequences, added to the human lives that are placed at risk.

\section{Data Availability}

Previously reported budget, accidents, and traffic data were used to support this study and are mainly available at Government of Spain pages (https://www.fomento.gob.es; http://www.dgt.es). These prior datasets are cited at relevant places within the text as [21-26, 31].

\section{Conflicts of Interest}

The authors declare that there are no conflicts of interest regarding the publication of this paper.

\section{Acknowledgments}

This research has been developed within the frame support of the University of Burgos (Spain).

\section{References}

[1] S. Hakim, D. Shefer, A. S. Hakkert, and I. Hocherman, "A critical review of macro models for road accidents," Accident Analysis \& Prevention, vol. 23, no. 5, pp. 379-400, 1991.

[2] X. Zou and W. L. Yue, "A bayesian network approach to causation analysis of road accidents using netica," Journal of Advanced Transportation, vol. 2017, Article ID 2525481, 18 pages, 2017.

[3] S. M. Rifaat and H. C. Chin, "Accident severity analysis using ordered probit model," Journal of Advanced Transportation, vol. 41, no. 1, pp. 91-114, 2007.

[4] H.-C. Chin and E. Tan, "Evaluating safety performance of road projects," Proceedings of the Institution of Civil Engineers: Transport, vol. 153, no. 3, pp. 191-196, 2002.

[5] P. de Leur and T. Sayed, "Development of a road safety risk index," Transportation Research Record, no. 1784, pp. 33-42, 2002.

[6] E. Hermans, F. Van den, and G. Bosscheand, "Combining road safety information in a performance index," Accident Analysis Prevention, vol. 40, no. 4, pp. 1337-1344, 2008.
[7] P. Holló, V. Eksler, and J. Zukowska, "Road safety performance indicators and their explanatory value: A critical view based on the experience of Central European countries," Safety Science, vol. 48, no. 9, pp. 1142-1150, 2010.

[8] F. L. Mannering, V. Shankar, and C. R. Bhat, "Unobserved heterogeneity and the statistical analysis of highway accident data," Analytic Methods in Accident Research, vol. 11, pp. 1-16, 2016.

[9] S. Kumar, D. Toshniwal, and M. Parida, "A comparative analysis of heterogeneity in road accident data using data mining techniques," Evolving Systems, vol. 8, no. 2, pp. 147-155, 2017.

[10] M. Imprialou and M. Quddus, "Crash data quality for road safety research: current state and future directions," Accident Analysis \& Preventio, 2017.

[11] G. J. S. Wilde, "Economics and accidents: a commentary," Journal of Applied Behavior Analysis, vol. 24, no. 1, pp. 81-84, 1991.

[12] J. G. U. Adams, Risk and freedom, Transport Publishing Projects, UK, 1985.

[13] G. W. Mercer, "Influences on passenger vehicle casualty accident frequency and severity: Unemployment, driver gender, driver age, drinking driving and restraint device use," Accident Analysis \& Prevention, vol. 19, no. 3, pp. 231-236, 1987.

[14] S. C. Partyka, "Simple models of fatality trends using employment and population data," Accident Analysis \& Prevention, vol. 16, no. 3, pp. 211-222, 1984.

[15] M. Rojo, H. Gonzalo-Orden, A. Linares, and L. Dell'Olio, "Effects of economic recession on road safety indexes," Transportation Research Procedia, vol. 18, pp. 80-87, 2016.

[16] T. H. Law, R. S. R. Umar, S. Zulkaurnain, and S. Kulanthayan, "Impact of the effect of economic crisis and the targeted motorcycle safety programme on motorcycle-related accidents, injuries and fatalities in Malaysia," International Journal of Injury Control and Safety Promotion, vol. 12, no. 1, pp. 9-21, 2005.

[17] G. Yannis, E. Papadimitriou, and K. Folla, "Effect of GDP changes on road traffic fatalities," Safety Science, vol. 63, pp. 4249, 2014.

[18] Y. Yanqun, Z. Lin, H. Aixiu, X. Zheng, and S. M. Easa, "Evaluating highway traffic safety: an integrated approach," Journal of Advanced Transportation, vol. 2018, Article ID 4598985, 11 pages, 2018.

[19] K. Goniewicz, M. Goniewicz, W. Pawłowski, and P. Fiedor, "Road accident rates: strategies and programmes for improving road traffic safety," European Journal of Trauma and Emergency Surgery, vol. 42, no. 4, pp. 433-438, 2016.

[20] B. P. Y. Loo, S. C. Wong, W. T. Hung, and H. K. Lo, "A review of the road safety strategy in Hong Kong," Journal of Advanced Transportation, vol. 41, no. 1, pp. 3-37, 2007.

[21] Ministerio de Fomento (MFOM), Presupuestos Generales del Estado, Ministerio de Fomento, Spain Government, 2008-2017.

[22] Ministerio de Fomento (MFOM), Anuario Estadístico 20142016, Ministerio de Fomento, Spain Government, 2015-2017.

[23] Dirección General de Tráfico (DGT), Las Principales Cifras de la Siniestralidad Vial. España 2008-2016, Ministerio del Interior, Spain Government, 2009-2017.

[24] Dirección General de Tráfico (DGT), Balance de Seguridad Vial 2015, Ministerio del Interior, Spain Government, 2016.

[25] Dirección General de Tráfico (DGT), Anuario Estadístico de Accidentes 2015-2016, Ministerio del Interior, Spain Government, 2016-2017.

[26] Real Automóvil Club de Cataluña (RACC), Análisis del Estancamiento de la Siniestralidad en las Carreteras Españolas durante 2015, RACC Automóvil Club, Spain, 2016. 
[27] C. Kraemer, J. M. Pardillo, M. G. Romana, V. Sánchez, and M. A. del Val, Ingeniería de Carreteras, vol. 1, S. A. Mcgraw-Hill/ Interamericana de España, Spain, 2009.

[28] J. J. F. Commandeur, P. Wesemann, F. Bijleveld, V. Chhoun, and S. Sann, "Setting road safety targets in cambodia: a methodological demonstration using the latent risk time series model," Journal of Advanced Transportation, vol. 2017, Article ID 5798174, 9 pages, 2017.

[29] A. S. Hakkert, L. Braimaister, and I. Van Schagen, The uses of exposure and risk in road safety studies, SWOV Institute for Road Safety Research, The Netherlands, 2002.

[30] C. Y. Chan, B. Huang, X. Yan, and S. Richards, "Investigating effects of asphalt pavement conditions on traffic accidents in Tennessee based on the pavement management system (PMS)," Journal of Advanced Transportation, vol. 44, no. 3, pp. 150-161, 2010.

[31] FITSA - Fundación Instituto Tecnológico para la Seguridad del Automóvil, El valor de la seguridad vial. Conocer los costes de los accidentes de tráfico para invertir más en su prevención, FITSA Foundation, Spain, 2018.

[32] NZ Ministry of Transport, Social Cost of Road Crashes and Injuries 2015 Update, Financial, Economic and Statistical Analysis Team, Ministry of Transpor, New Zealand, 2015.

[33] Asociación Española de la Carretera, Nota de Prensa - Auditoría sobre el Estado de las Carreteras, Asociación Española de la Carretera, Spain, 2016, https://www.aecarretera.com/np/NP\%20 Auditoria\%20estado\%20carreteras\%20AEC\%202015\%202016_ v3.pdf. 


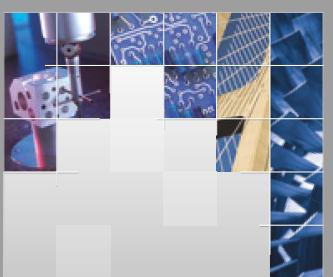

\section{Enfincering}
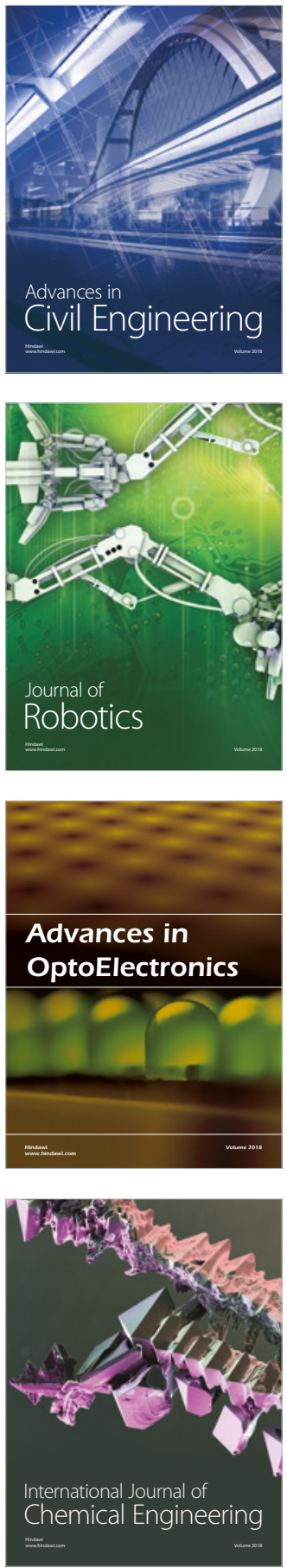

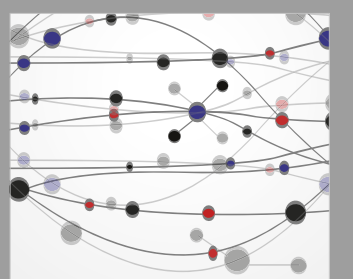

\section{Rotating \\ Machinery}

The Scientific World Journal

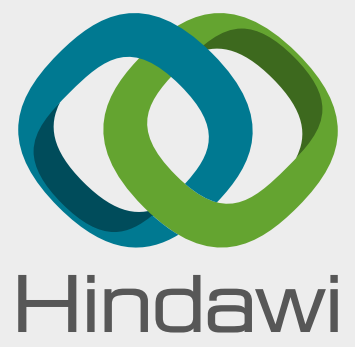

Submit your manuscripts at

www.hindawi.com
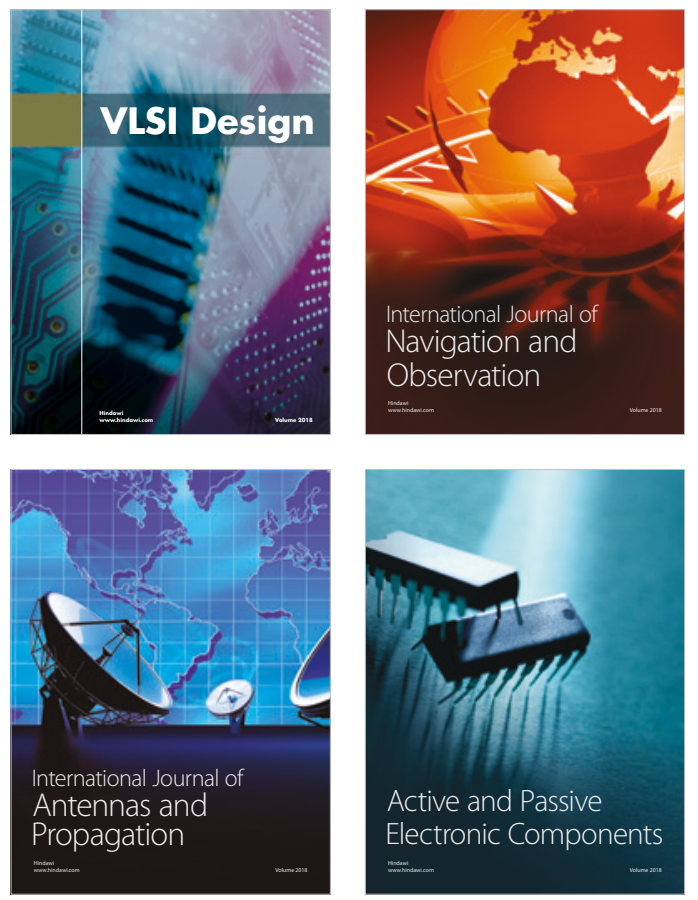
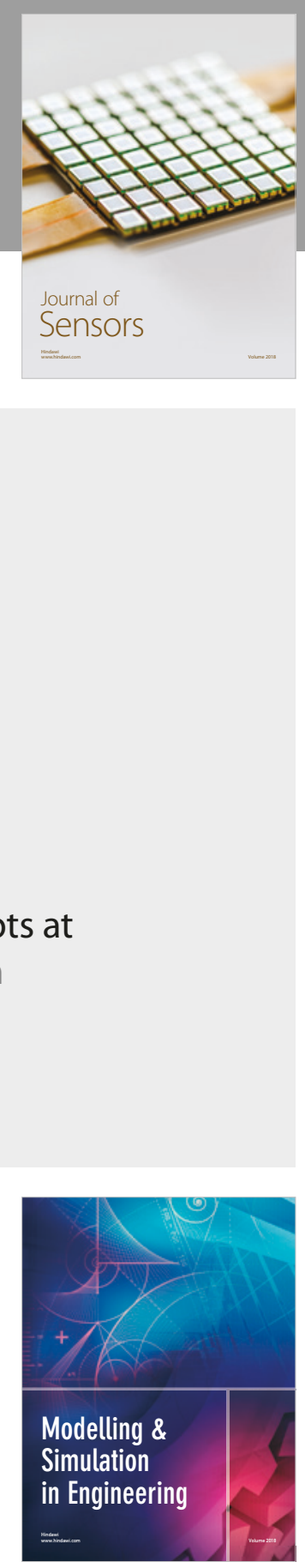

\section{Advances \\ Multimedia}
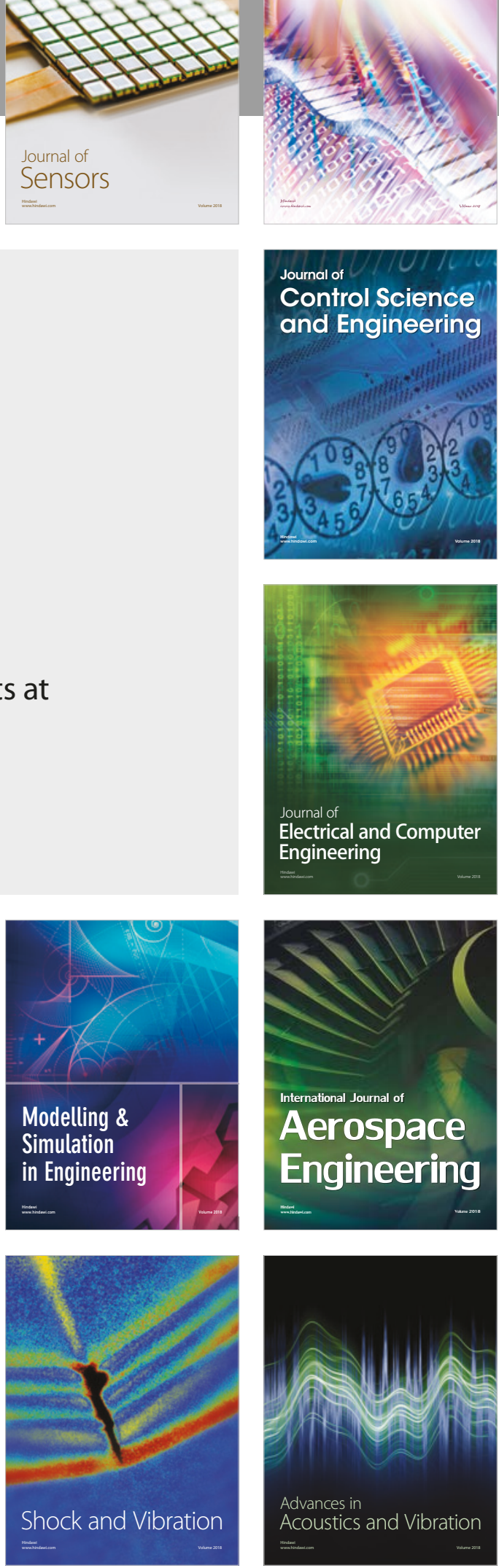